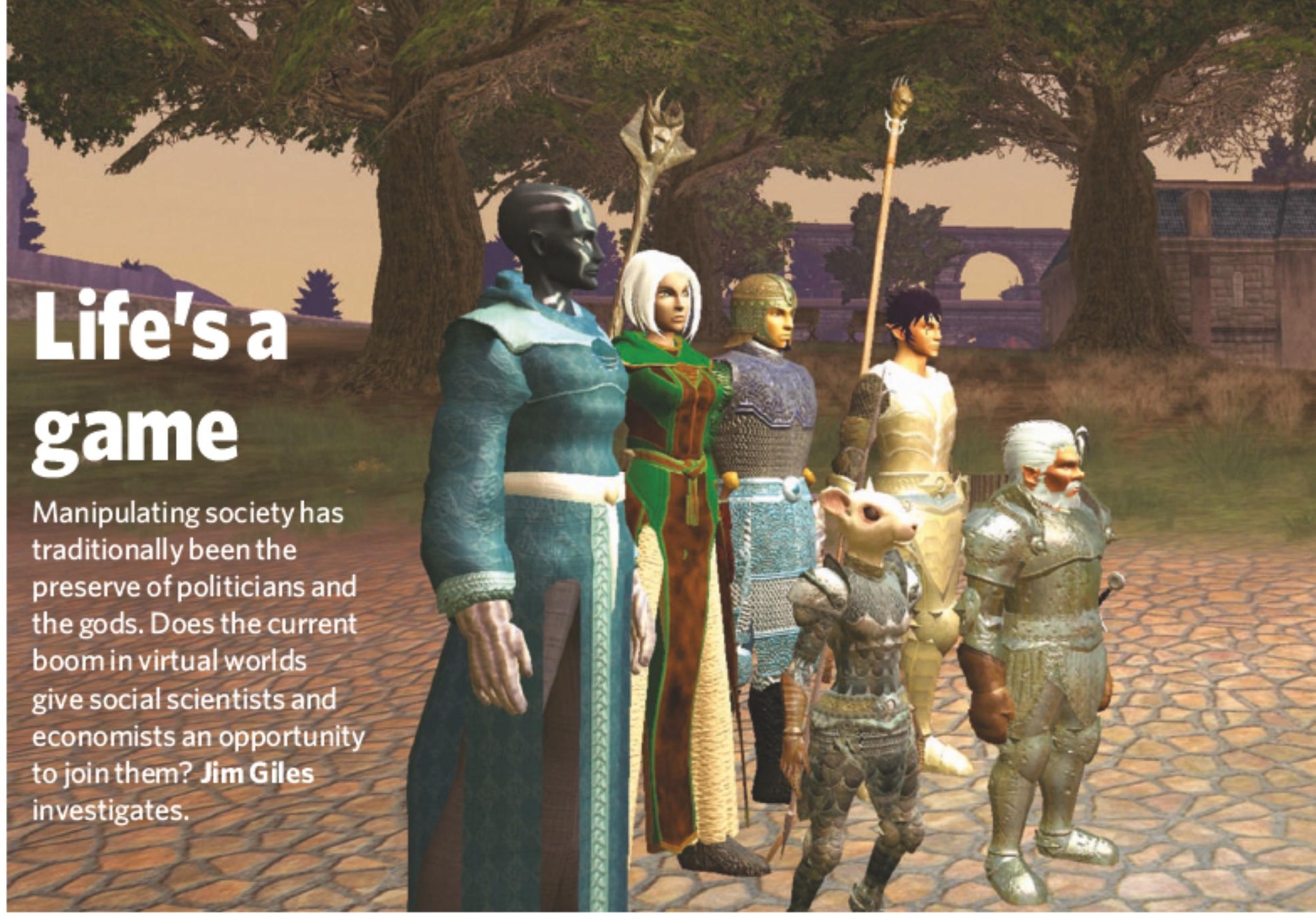

$s$ a ruthless dictatorship a better way of running a country than a well-oiled democracy? Would people be happier if all their property was confiscated? Might our economies be healthier if inflation ran at $100 \%$ ?

We're sure we know the answers. Kim Jong-il's reign in North Korea is a brutal one. Hyperinflation is wrecking Zimbabwe. History tells us that stealing land prompts wars, not happiness. By comparing these and other examples, we can be confident that each proposal is, well, foolish.

But how would an experimental scientist view this kind of knowledge? Many physicists answer questions by running experiments, tweaking conditions and recording the results. They do so repeatedly, until the role of every variable is understood. Case studies are the beginning of the process, not the end. And physical laws are not limited to observations of what approach seems to work best; they can produce complex models that allow predictions of the future.

The difference in approach is no reflection on the abilities of social scientists. It's just that societies are not so amenable to experimentation. Government economists would not be popular if they repeatedly tweaked monetary policy just to see what happened. Social scientists learn from history. They run surveys. They even conduct small experiments with a handful of subjects in idealized conditions. What they can't do is manipulate the system they are studying.

Enter Edward Castronova, an economist at Indiana University in Bloomington, occasional writer of fiction and an expert on multiplayer online games. His vision is nothing if not ambitious: to create societies with the intention of experimenting on them. The societies will exist only inside computers, with real people living some of their lives through characters (avatars) in these virtual worlds. But Castronova does not intend to merely simulate real life. $\mathrm{He}$ and other researchers want to tweak the rules of those worlds so they can study everything from democracy to monetary policy. Such tools, says Castronova, would be the "supercolliders" for his field. They would usher in an era of "computational social science".

\section{Parallel worlds}

If that sounds unlikely, visit Azeroth. You'll have plenty of company: more than seven million people play World of Warcraft, the online role-playing game that is based in this virtual realm. The game, run by Blizzard Entertainment of Irvine, California, is pure axe-wielding tolkienian fantasy: players go on quests and slay mythical beasts, amass- ing virtual wealth and power in the process. Nevertheless, Azeroth society shares many features with our own. Players produce goods and trade them; they cooperate to achieve goals but also conduct personal vendettas; some are unhelpful and rude, others - admittedly not many - display altruism.

Elsewhere in cyberspace, economies are springing up that, superficially at least, seem to mirror the real world. Cyber-capitalism is most apparent in the malls of Second Life, an online world that is visited by around 10,000 people a day. The world's designers, Linden Lab of San Francisco, have eschewed fantasy quests and given users the tools and virtual land they need to build their own online experience. Since Second Life's launch in 2003, universities have leased space to teach dasses, and high-street retailers have set up outlets where avatars can get their hair cut or buy virtual roller-skates. The inworld currency now floats against the dollar on dedicated exchanges, and one user claimed last November that her Second Life property business has made her a real-world millionaire.

Virtual worlds also show similarities to real life at the level of one-on-one social interactions (despite many players choosing outlandish avatars such as giant mice). In a paper in press with CyberPsychology \& Behavior, Nick 
Yee at Stanford University, California, shows that some of the unwritten rules of real-life socializing appear to cross over into Second Life, even though communication is purely text based. Male avatars stand further apart than females when talking, for instance, and tend to make less eye contact.

If these cyber-societies follow some of the rules of real life, what can social scientists do with them? Many want to treat them like a biologist treats cells in a Petri dish. Tinker with monetary policy. Rewrite the rules of democracy. Force players to work together, or try and drive them apart. But conduct each intervention in a systematic way, holding all other variables constant and rigorously monitoring the outcomes. Thanks to the huge audiences that online games attract, social scientists will then be manipulating society itself. Although a full "supercollider" experiment has not yet been done, tentative steps have been taken, and the results suggest that the idea has merit.

\section{Location, location}

First up was a study of a seemingly trivial question: why are certain businesses based in specific places? The answer is also apparently trivial: they are there because we say they are. It makes sense for actors and film producers to agree that movies are made in Hollywood and Mumbai. Anyone who wants to be in the film business then knows where to go. There is nothing that compels movie stars to behave in this way, except that everyone involved agrees on the location - what social scientists call a 'coordination effect'.

At least that's one theory. One can also argue that there is something special about Hollywood or Mumbai that means that movies get made there, for example, and that coordination effects are less important. It has been hard to settle the argument either way, which undermines attempts by economists to explain how societies reach such agreements. That then hampers our understanding of bigger questions, such as how cooperative behaviour evolved to become such a prominent feature of everyday life.

This uncertainty persists in part because social scientists have only limited ways of studying coordination effects in real life. Distinguishing between rival explanations is tricky because we can't re-run history and, for example, probe the factors that drew movie moguls to California in the first place.

Except that now we can, because some virtual worlds regularly recreate themselves to cope with overcrowding. Take Norrath, the land in the fantasy game EverQuest. After launching in 1999, EverQuest's blend of trolls and spells proved so popular that Sony Online Entertainment, which runs the game, created additional copies of Norrath on multiple servers. There are currently 26 servers running. And each time Sony creates another world, a new society evolves under almost exactly identical starting conditions.

This cloning of worlds gave Castronova his

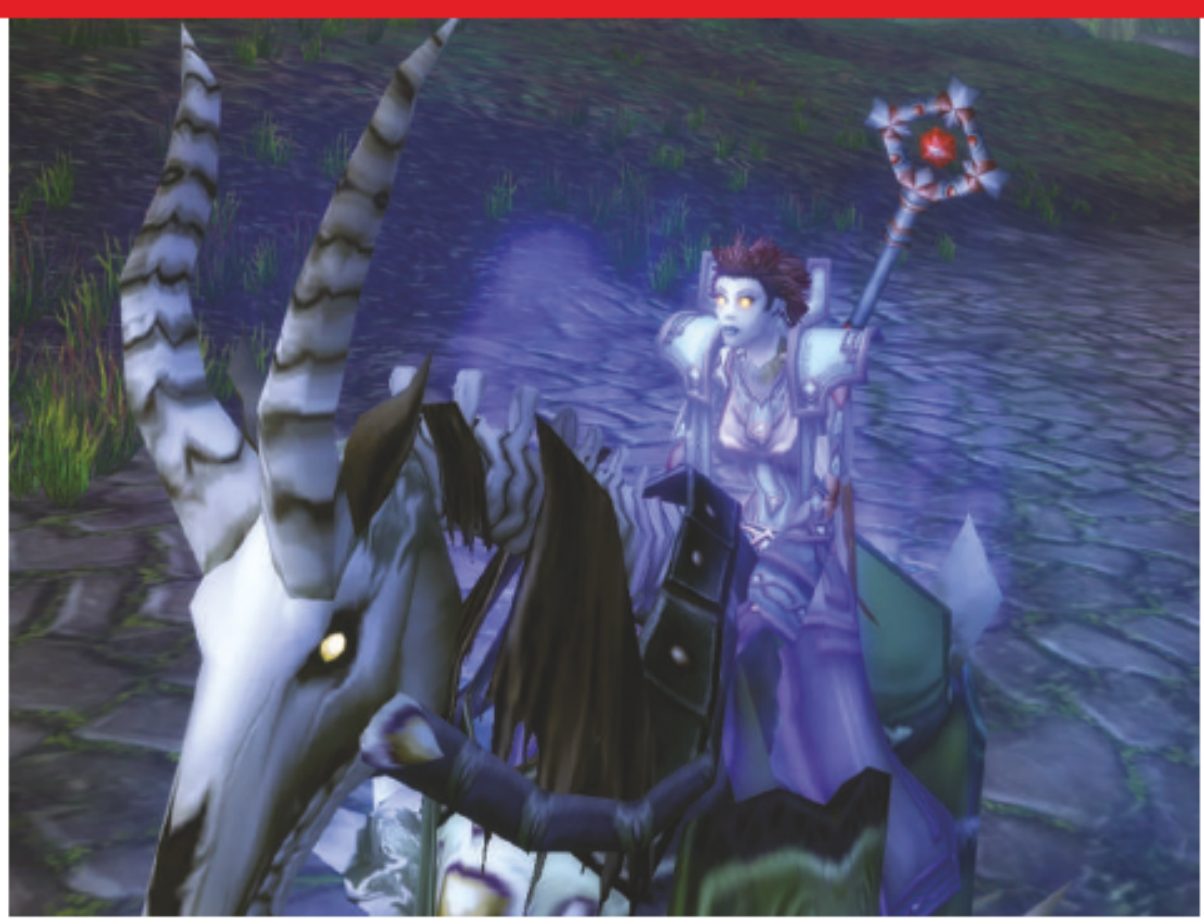

Multiplayer games like World of Warcraft attract millions of online players. first chance to do computational social science. Using a survey of EverQuest players (E. Castronova Games and Culture 1, 163-186; 2006), he showed that on each server just one region has become established as a market. Crucially, that region differs between servers, although mountain ranges and cities have identical locations in all the worlds. So there does not seem to be a single prime location for the market; instead, some chance event seeds its creation, and coordination effects then lock it into place. "With no small amount of trepidation,"

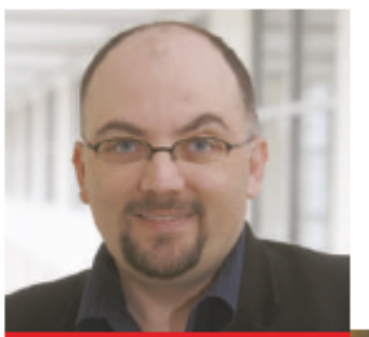

Castronovahas his own online avatar in World of Warcraft (below) and is now creating a world of his own. world.
Castronova writes in a footnote to the paper, "I would venture to claim that this is the first time in human history that a distinct macrosocial phenomenon has actually been verified experimentally."

For Castronova, this result hints at what could be achieved. But other social scientists are more sceptical. When Nature contacted authors of some highly cited papers on coordination effects, they expressed interest in Castronova's approach, but none had yet read his paper. After doing so, they highlighted various shortcomings they saw in the study.

Some took issue with the paper's more grandiose statements. Castronova's "trepidation" is well justified, says Andrew Colman, a game theorist at the University of Leicester, UK. Colman's laboratory studies of coordination effects, along with other work, had indicated their importance before Castronova's study. And Colman's studies involve more than 80

\section{"Tools for}

manipulating online

worlds would

usher in an era of

computational

social science" -

Edward Castronova

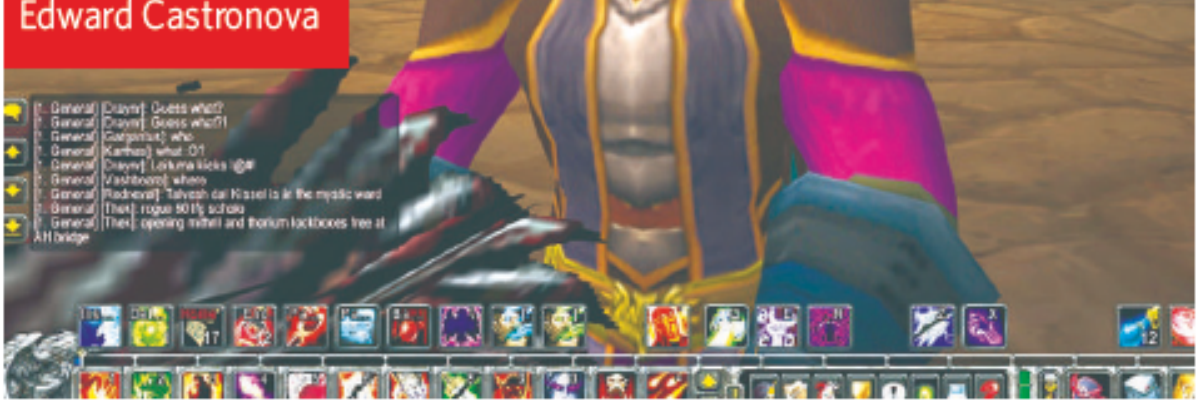


students - around the same number of players from each server that responded to Castronova's survey. Other researchers questioned whether the worlds that Castronova studied are truly independent, as it would be possible for players to communicate outside the game.

Castronova acknowledges that lab work has already shown that coordination effects are real, and says that although his study needed just a few survey respondents to identify the market location, the coordination effect resulted from the interaction of hundreds of thousands of people. 'It's a dramatic difference in terms of scale and complexity." Researchers might, for example, be interested in how coordination effects are influenced by information campaigns run by governments - an issue that is beyond the scope of lab work.

But the biggest criticism of this approach is one that all virtual-world experiments will have to face: "The number-one challenge is generalizability to the real world," says Dmitri Williams, a social scientist at the University of Illinois at Urbana-Champaign, who is credited along with Castronova for developing the idea of using virtual worlds to study real society.

To illustrate the problem, Williams points to a 'plague' that broke out in World of Warcraft in summer 2005. At first, says Williams, researchers proposed that the spread of the disease could be used as a model for real-world epidemiology. But it soon became clear that some players were deliberately infecting others, because, unlike in real life, they suffered little penalty for doing so. Players are also much more willing to risk death online than they are in the real world. "The risks don't match up," says Williams, "so we have to be very careful about generalizing our conclusions."

Nevertheless, Williams is keen to use virtual worlds to examine theories about how communities form. Like many of those working on virtual worlds, he feels that data from these experiments complement rather than replace those from traditional social-science studies.

Castronova agrees, adding that watching mice in mazes does not reveal everything about how the human brain works, but it does give researchers another way of studying the issue. For now, the only 'mice' that Castronova and others can study are those playing games such as EverQuest. The designers have often welcomed researchers who want to study cyber-societies, but this partnership can go only so far. Game companies cannot be expected to mess with their profitable products to please social scientists, so to realize his goal, Castronova needs to build his own world to rule over.

That world, or at least a prototype, should be here soon. Using a one-year grant of $\$ 250,000$ from the John D. and Catherine T. MacArthur Foundation, based in Chicago, Illinois, Castronova and his colleagues are building the Shakespeare-themed world of Arden. Fifteenth-century maps of the English county of Somerset will define a landscape over which blacksmiths, tavern-keepers and bards will roam. A test version should be up and running by March, and its results might enable Castronova to attract the funding needed to build a fully functional version. Ultimately, he wants around 500 people to play for 100 hours per month each - enough to provide a functioning economy. The players will be there because it's fun.

To run economic experiments of interest to Castronova, Arden will need to develop an economy that features aspects of the real world, such as inflation. By building different monetary conditions into different versions of

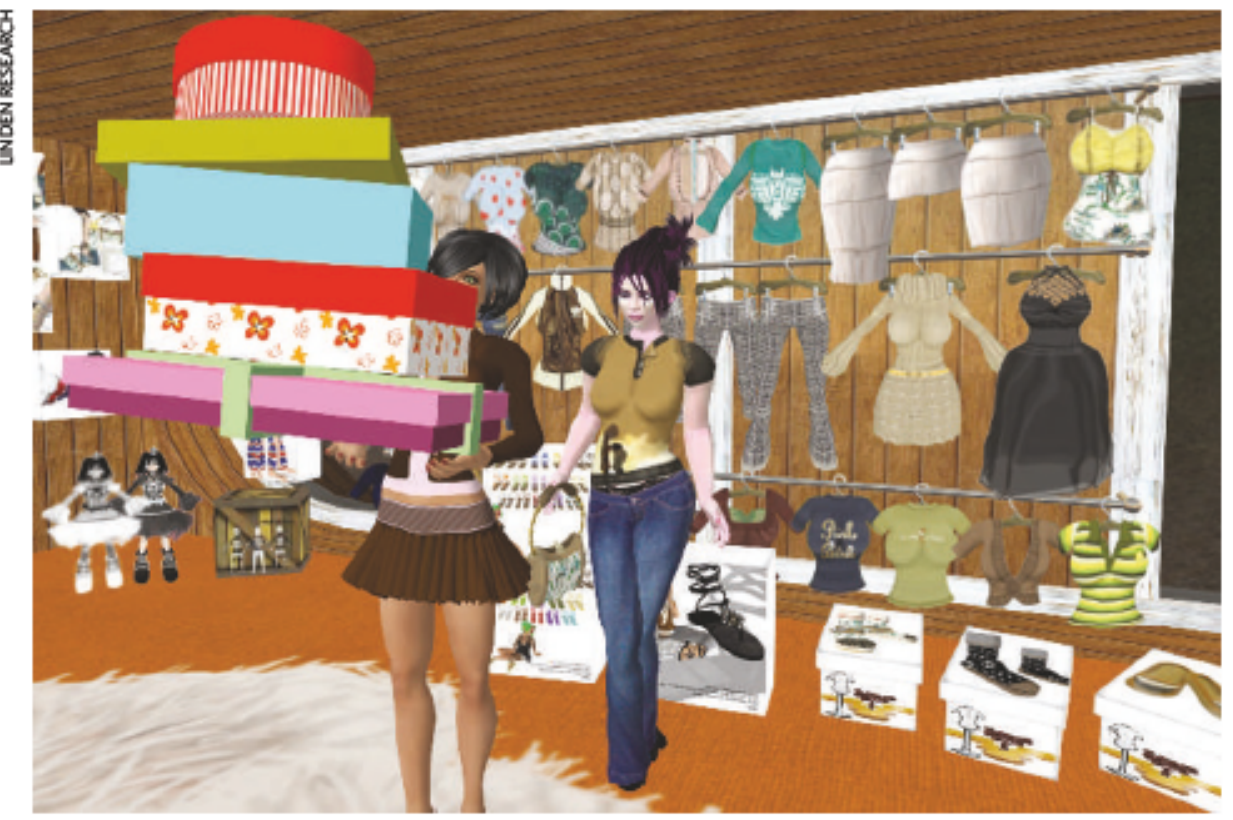

Does shopping for virtual goods imitate shopping habits in reallife?
Arden, Castronova will be able to test aspects of economic theory such as supply and demand. With two versions of Arden with different prices for a particular good, theory says that demand should be higher in the world where the good costs less. This is just an example, as Castronova will not reveal exactly what experiment he is planning for fear of invalidating the study.

Arden could in principle be used to test any idea that interests social scientists. One might examine how laws influence individual behaviour, suggests law researcher Dan Hunter of the University of Pennsylvania in Philadelphia. Others want to test new forms of democratic participation or assumptions in marketing theory.

\section{Reality check}

Enthusiasm is no promise of success, however. Perhaps the most immediate problem facing Castronova's team, if they secure longer-term funding, will be game design. Sony's multimillion-dollar budget buys teams of experienced game designers. Castronova has around 30 committed but less qualified members of his university. He must also balance the need to design a world that he can control for his research with the need to create an experience that is enjoyable enough to get people coming back. No university team has built a large-scale online game for research purposes before, and there is no guarantee of success.

Castronova will also have to grapple with the sometimes unanticipated ethical problems that arise in online research. In one study of the playing habits of online gamers, a group of USbased social scientists collected anonymized data from a game company. But researchers who were regular game players soon realized they had enough information to link avatars to people they knew.

Other problems may emerge as games become more popular. There is real money at stake in many games, and players have been known to contact the police over thefts of cyber-weapons. Greg Lastowka, at Rutgers School of Law in Camden, New Jersey, says that players may increasingly take real-world legal action to remedy online crimes, undermining the chances of testing new legal systems in the worlds themselves.

Computational social science is yet to prove itself as an established research method. Right now, admits Castronova, many social scientists dismiss such studies because they feature fantastical avatars in mythical quests. And to prove them wrong, solid results are needed. But as befits a man on a mission, Castronova is confident that he can provide them: ${ }^{\alpha}$ They'll believe us when we start showing it's possible".

Jim Giles is a reporter for Nature based in London. 